\title{
Fatty acid-binding protein 5 promotes cell proliferation and invasion in human intrahepatic cholangiocarcinoma
}

\author{
CHI-YOUNG JEONG $^{1 *}$, YOUNG-SOOL HAH ${ }^{2 *}$, BOK IM CHO $^{1}$, SEON MIN LEE ${ }^{1}$, \\ YOUNG-TAE JOO $^{1}$, EUN-JUNG JUNG ${ }^{1}$, SANG-HO JEONG ${ }^{1}$, YOUNG-JOON LEE ${ }^{1}$, \\ SANG-KYUNG CHOI ${ }^{1}$, WOO-SONG HA ${ }^{1}$, SOON-TAE PARK ${ }^{1}$ and SOON-CHAN HONG ${ }^{1}$ \\ ${ }^{1}$ Department of Surgery, Gyeongsang National University School of Medicine, Institute of Health Sciences, \\ Gyeongsang National University Hospital; ${ }^{2}$ Clinical Research Institute, Gyeongsang \\ National University Hospital, Jinju 660-751, Republic of Korea
}

Received May 4, 2012; Accepted June 21, 2012

DOI: $10.3892 /$ or.2012.1922

\begin{abstract}
Intrahepatic cholangiocarcinoma (ICC) is a rare primary malignant liver tumor with an extremely poor prognosis. Recently its incidence has increased, however, little attention has been directed to factors related to its molecular carcinogenesis, including oncogenes, tumor suppressor genes and cell cycle-related proteins. ICC is generally characterized by strong proliferation, invasion and early metastasis. These biological behaviors of ICC, with respect to the genetic and molecular aspects, remain to be clarified. In this study, we performed a proteomic analysis to identify the proteomic alterations associated with carcinogenesis of ICC. Protein expression profiles of sixteen cases of ICC were compared with those of adjacent non-involved bile duct tissue. Among the 151 protein spots that showed a statistically significant expression difference $(\mathrm{P}<0.05)$, there were 50 spots with significantly increased intensity (3-fold increase) and 17 spots with decreased intensity (3-fold decrease) in cancerous tissues. Of these, increased expression of fatty acid-binding protein 5 (FABP5) was further confirmed by western blot analysis and immunohistochemical analysis. Immunohistochemical analysis of FABP5 expression in tumor specimens obtained from 43 patients with mass-forming (MF) type ICC showed a positive correlation of FABP5 immunoreactivity with tumor size $(\mathrm{P}=0.047)$, lymph node metastasis $(\mathrm{P}=0.013)$, angioinva-
\end{abstract}

Correspondence to: Dr Soon-Chan Hong, Department of Surgery, Gyeongsang National University School of Medicine, Institute of Health Sciences, Gyeongsang National University Hospital, Jinju 660-751, Republic of Korea

E-mail: hongsc@gnu.ac.kr

*Contributed equally

Key words: intrahepatic cholangiocarcinoma, fatty acid-binding protein 5 , proteome, invasion, proliferation sion $(\mathrm{P}=0.032)$ and staging $(\mathrm{P}=0.007)$. In addition, silencing FABP5 with short hairpin RNA (shRNA) suppressed cell proliferation and invasiveness in HuCCT1 cells, and conversely, overexpression of FABP5 in FABP5-negative Hep3B cells increased cell proliferation and invasiveness. Our study shows that FABP5 is significantly overexpressed in ICC combined lymph node metastasis and is involved in cell proliferation and invasion in vitro. Our data suggest that FABP5 may be associated with tumor progression in ICC.

\section{Introduction}

Intrahepatic cholangiocarcinoma (ICC) is the second most common type of primary liver cancer. It arises from the second or more distal branches of intrahepatic bile ducts. Although ICC accounts for only $5-15 \%$ of primary liver malignancies, its incidence and cancer-related mortality continues to rise. The causes for this increasing incidence remain unknown and may be related to predisposing genetic and environmental factors (1). Surgical resection has been shown to improve long-term survival of patients with ICC, but the resectibility rate for this cancer is low and the outcome even after resection still remains disappointing. The reasons are likely that early diagnosis of ICC is difficult and currently no effective treatment in the advanced stages of the disease is available $(2,3)$. Clinicopathologic factors such as tumor size, differentiation, gross type, cancer-free margin, vascular invasion, and lymph node metastasis have been reported to be significant prognositic factors $(3,4)$. Despite the recent advances in disease detection and treatment, the predicted outcome for ICC remains dismal, partly because of limited knowledge of the molecular processes involved in pathogenesis and failure to detect the disease in the early stages. Therefore, it is critical to identify biomarkers that enable early diagnosis, provide insight into pathogenesis of the disease, and develop more effective treatment options.

Fatty acid-binding proteins (FABPs) are members of the intracellular lipid-binding protein family and are abundantly expressed 14-15-kDa proteins that reversibly bind intracellular hydrophobic ligands $(5,6)$. These proteins are thought 
to be involved in the uptake and intracellular transport of fatty acids. In addition, they play many roles in gene regulation, cell signaling, cell growth and differentiation (7). FABP5, also known as psoriasis-associated fatty acid-binding protein (PA-FABP), epidermal or cutaneous fatty acid-binding protein (E- or C-FABP) was originally isolated from psoriatic skin samples (8). It was later found to be expressed in many other tissues, including mammary gland (9). Several recent studies have reported that FABP5 was very strongly expressed in pancreas, bladder and prostate cancers (10-12), indicating that FABP5 may also play a role in malignant progression in these tissues. Although the precise role of FABP5 in these tissues is not clear, it is likely to be involved in binding and transporting intracellular fatty acids, some of which are signaling molecules reported to be involved in the regulation of gene expression $(13,14)$.

In the current study, we analyzed differential expression profiles of human ICC and normal tissue specimens, examined the expression of FABP5 protein in clinical ICC specimens, and assessed the relationship between FABP5 expression pattern and known clinicopathological variables. In addition, we investigated the effect of stable overexpression and knockdown of FABP5 on cancer cell proliferation and invasion to determine whether FABP5 contributes to carcinogenesis of cholangiocarcinoma. We report that FABP5 is significantly overexpressed in ICC, and associated with tumor size, lymph node metastasis, angio-invasion and TNM (tumor, node and metastasis) staging. Moreover, FABP5 expression promotes cancer cell proliferation and invasion.

\section{Materials and methods}

Patients and tissue samples. Pairs of cancerous and normal tissues diagnosed by a pathologist were collected from sixteen patients with MF type ICC who underwent radical or palliative surgical procedures at Gyeongsang National University Hospital (GNUH) during the period 20062009. The clinical data collected included age, gender, differentiation, operation type and TNM stage. None of the patients received preoperative chemotherapy or radiotherapy. Informed patient consent was obtained for all of the cases. The use of the tissue samples for this project was approved by the GNUH Institutional Review Board. Cancerous lesions and the corresponding normal bile duct tissues were excised during surgery and stored at $-70^{\circ} \mathrm{C}$ for proteomic analysis and further study.

Protein extraction and two-dimensional gel electrophoresis (2-DE). Tissue samples (150-200 mg) were homogenized on ice in $1 \mathrm{ml}$ homogenization buffer (50 mM Tris-HCl, $\mathrm{pH} 7.2)$ containing a protease inhibitor cocktail (Sigma-Aldrich, St. Louis, MO, USA). The homogenate was centrifuged, followed by TCA precipitation. The protein precipitate was resuspended in lysis buffer (8 M urea, 4\% CHAPS, $40 \mathrm{mM}$ Tris-base, $100 \mathrm{mM}$ DTT and $2 \%(\mathrm{w} / \mathrm{v})$ ampholyte) and the protein concentration was measured using Bradford method with Protein assay kit (Bio-Rad Laboratories, Hercules, CA). Equal amounts of protein extracts of each tissue samples $(50 \mu \mathrm{g}$ for silver-stained gels or up to $0.5 \mathrm{mg}$ for Coomassie-stained gels) were subjected to isoelectric focusing ( $\mathrm{pH} 4.0$ to 7.0 ) and sequentially a gradient SDS-polyacrylamide gel (7.5-17.5\%) electrophoresis as previously described (15).

Protein visualization and image analysis. Separated twodimensional gels were fixed and then pretreated in a solution of $0.02 \%$ sodium thiosulfate pentahydrate. After washing twice with deionized water, the gels were impregnated in a solution of $0.2 \%$ silver nitrate and $0.075 \%(\mathrm{v} / \mathrm{v})$ formaldehyde, transferred to a developing solution $[0.06 \%(\mathrm{v} / \mathrm{v})$ formaldehyde, $2 \%$ sodium bicarbonate, and $0.0004 \%$ sodium sulfoxide]. For Coomassie staining, the gels were fixed and rinsed twice in $2 \%$ phosphoric acid. The gels were placed in equilibration (18\% ethanol, $2 \%$ phosphoric acid and $15 \%$ ammonium sulfate) followed by overnight staining with Coomassie Brilliant Blue G-250 solution. The gels were scanned using a high resolution scanner (GS-800 Calibrated Imaging Densitometer, Bio-Rad Laboratories) and analyzed using PDQuest ${ }^{\mathrm{TM}}$ version 8.0. software (Bio-Rad Laboratories). The intensity of each spot was quantified by calculating the spot volume after normalization of the gel image.

In-gel digestion. Selected protein spots were excised from 2-DE gels that had been stained with Coomassie blue G-250. Gel pieces first were destained with water/acetonitrile (1:1 $\mathrm{v} / \mathrm{v}$ ) then dehydrated in acetonitrile followed by rehydration in $10 \mathrm{mM} \mathrm{DTT} / 0.1 \mathrm{M}$ ammonium bicarbonate for $45 \mathrm{~min}$ at $56^{\circ} \mathrm{C}$. After cooling the tubes to room temperature and removing the liquid, $55 \mathrm{mM}$ iodoacetamide in $0.1 \mathrm{M}$ ammonium bicarbonate was added and the tubes were incubated for $30 \mathrm{~min}$ at room temperature in the dark. The iodoacetamide solution was removed and the gel particles were washed with $0.1 \mathrm{M}$ ammonium bicarbonate and acetonitrile and then dried in a vacuum centrifuge. The dried gel pieces were incubated in freshly prepared digestion buffer containing $50 \mathrm{mM}$ ammonium bicarbonate, $5 \mathrm{mM} \mathrm{CaCl}_{2}$, and $12.5 \mathrm{ng} / \mu 1$ trypsin overnight at $37^{\circ} \mathrm{C}$. The supernatant was then collected and the digested peptides extracted three times in $5 \%$ formic acid/ acetonitrile $(1: 1 \mathrm{v} / \mathrm{v})$

Matrix assisted laser desorption/ionization-time of flightmass spectrometry (MALDI-TOF-MS) and database search. The digested peptides were redissolved in a solution containing water, acetonitrile, and trifluoroacetic acid (93:5:2 by volume) and sonicated for $5 \mathrm{~min}$ in a bath sonicator. Target preparation was carried out by the 'solution phase nitrocellulose method' described by Landry et al (16). Briefly, a saturated solution of $\alpha$-cyano-4-hydroxycinnamic acid (CHCA; $40 \mathrm{mg} / \mathrm{ml}$ ) and nitrocellulose solution $(20 \mathrm{mg} / \mathrm{ml})$ were prepared separately in acetone and mixed with 2-propanol at a ratio of 2:1:1, respectively. Internal calibrants (50-200 fmole each), des-Argbradykinin (monoisotopic mass $=904.4681$ ), and neurotensin (monoisotopic mass $=1672.9715)$ were added to the mixture . The matrix solution was mixed with the sample at a 1:1 ratio, and $1 \mu \mathrm{l}$ of mixed sample was spotted onto a MALDI plate. The dried spots were analyzed with a Voyager-DE STR MALDI-TOF mass spectrometer (Applied Biosystems, Foster City, CA). The identity of the proteins was assigned by comparing the observed mass fingerprint with the predicted mass fingerprint of proteins in the SWISS-Prot and NCBI databases using the MS-Fit search program (17). 
Western blot analysis. Lysates (40 $\mu \mathrm{g})$ from ICC and its corresponding normal bile duct tissues from 16 patients were separated by on a $15 \%$ SDS-polyacrylamide gel. The separated proteins were transferred to a PVDF membrane by electroblotting. The membrane was blocked for $1 \mathrm{~h}$ in TBST solution (Tris-buffed saline, $20 \mathrm{mM}$ Tris- $\mathrm{HCl}, \mathrm{pH} 7.6,137 \mathrm{mM} \mathrm{NaCl}$, and $0.1 \%$ Tween-20) containing 5\% skim milk. After blocking, the membranes were washed in TBST twice for $10 \mathrm{~min}$ each and incubated with anti-FABP5 rabbit polyclonal antibody for $1 \mathrm{~h}$ at room temperature. After additional washes with TBST, the membranes were incubated with secondary anti-rabbit IgG $(1: 10,000)$ for $1 \mathrm{~h}$. After final washes, proteins were visualized by the enhanced chemiluminescence method (Pierce, Rockford, IL). $\beta$-actin was used as a loading control in the stripped blot.

Immunohistochemistry. Formalin-fixed, paraffin-embedded tissue blocks from 43 patients with MF-ICC were collected, sectioned at $4 \mu \mathrm{m}$ and mounted on slides. The slides were deparaffinized and rehydrated in a graded alcohol series, and pretreated with $10 \mathrm{mM}$ sodium citrate. Immunostaining was performed with a rabbit polyclonal FABP5 antibody (1:500) using an LSAB kit (Dako, Glostrup, Denmark). Antigen retrieval was facilitated by microwaving the tissue for $15 \mathrm{~min}$, and the staining procedure was carried out according to the standard avidin-biotin-peroxidase complex system previously described (18). Immunohistochemical staining was interpretated and categorized by an arbitrary semi-quantitative scale as 0 (negative staining), +1 (0 20\% positive), $+2(20 \sim 40 \%$ positive), or +3 ( $>40 \%$ positive) by pathologists. The staining intensity was also simply categorized into 'weak' $(0$ to +1$)$ and 'strong' $(+2$ to +3$)$ groups. Tumor size, degree of differentiation, lymph node metastasis, vascular invasion, perineural invasion and multiplicity were included in the clinicopathological information (Table III).

Cell culture and transfection. HuCCT1 cell line was purchased from the Health Science Research Resources Bank (Osaka, Japan). HuCCT1 cells were cultured with RPMI-1640, 10\% fetal bovine serum (FBS) and $1 \mathrm{X}$ penicillin/streptomycin at $37^{\circ} \mathrm{C}$ in $5 \% \mathrm{CO}_{2}$ incubator. Human hepatoma cell line, Hep3B were maintained in DMEM supplemented with $10 \%$ FBS and $1 \mathrm{X}$ antibiotics in a humidified atmosphere containing $5 \% \mathrm{CO}_{2}$ and $95 \%$ air at $37^{\circ} \mathrm{C}$. Human FABP5 cDNA was cloned into pcDNA3.1 using standard RT-PCR procedures. The empty vector was used as a control for possible effects caused by the transfected plasmid. The constructs were transfected into Hep3B cells using Lipofectamine 2000 (Invitrogen, Carlsbad, CA) according to the manufacturer's protocol and stable FABP5-expressing cell lines were selected by G418 (2 $\mathrm{mg} / \mathrm{ml})$.

Short-hairpin RNA-mediated FABP5-gene silencing. The MISSION shRNA bacterial glycerol stock containing 5 anti-FABP5 shRNA sequences and the SHC002 shRNA Control were purchased from Sigma-Aldrich. The shRNA constructs were transfected into HuCCT1 cells using a reagent (Lipofectamine 2000; Invitrogen) according to the manufacturer's instructions. Stable shRNA-expressing cell lines were established and selected by puromycin $(2 \mu \mathrm{g} / \mathrm{ml})$.
Results from shRNA TRCN0000059720 are presented in this report.

Proliferation assay and invasion assay. For proliferation assay, cells were placed in a 6 -well plate at a concentration of $1 \times 10^{5}$ cells/well. After incubation for 1-3 days, the viable cells were counted with a hemocytometer after trypan blue staining. Invasion assays were performed on 24-well transwells (Costar, Cambridge, MA, USA) with polycarbonate filters $(8 \mu \mathrm{m}$ pore size). The transwells for invation assays were coated with a uniform layer of BD Matrigel ${ }^{\mathrm{TM}}$ Basement Membrane Matrix (BD Biosciences, Bedford, MA, USA). The stable cell lines were resuspended in RPMI-1640 or DMEM containing $10 \%$ FBS and seeded into the upper wells $\left(1 \times 10^{5}\right.$ cells/well) and incubated at $37^{\circ} \mathrm{C}$ for $24 \mathrm{~h}$. Invaded cells were fixed in $4 \%$ PFA, stained with DAPI, and counted under the fluorescent microscope at x100 magnification for 5 random fields.

Statistical analysis. Statistical analysis was performed by the Chi-squared test using the SPSS program (version 11.0). All P-values were based on a two-tailed statistical analysis, and P-values of $<0.05$ were considered statistically significant.

\section{Results}

Proteomic analysis of ICC. We analyzed the proteomic profiles of the ICC tissue and corresponding normal bile duct tissues from 16 patients to establish a tumor specific protein expression profile. The upregulated or downregulated protein expressions between the ICC tissue samples and their healthy counterparts were evaluated using PDQuest ${ }^{\mathrm{TM}}$ software. By making comparison with PDQuest software quantification, the 151 protein spots that showed a statistically meaningful expression difference $(\mathrm{P}<0.05)$ were selected. The spots that showed more than a 3 -fold increase or decrease of intensity were defined as being the up- or downregulated proteins, respectively. According to this definition, among the 67 candidate protein spots, 50 proteins were upregulated and 17 proteins were downregulated in ICC tissue compared to the non-cancerous bile duct tissue. The protein spots were identified using MALDI-TOF-MS and the MS-FIT search program. The identities of the proteins were confirmed by comprehensively comparing the corresponding experimental value of isoelectric point (pI), molecular weight (MW), the number of matched peptides, and the sequence coverage to known proteins in the SWISS-PROT and NCBI databases. The lists of proteins that were found to be up- or downregulated in ICC tissue are shown in Tables I and II, respectively.

Verification of FABP5 expression in ICC tissue specimens by western blot analysis and immunohistochemistry. Among the identified proteins, the spot 6010 showed markedly increased intensity in all of investigated patients with an average increase of 4.49-fold (Fig. 1A). Statistical analysis of the spots confirmed that spot 6010 was significantly upregulated $(\mathrm{P}=0.0125)$ and subsequently identified as FABP5 by MALDI-TOF-MS, with a molecular mass of $15.2 \mathrm{kDa}$ and a pI 6.6. The sequence coverage of protein isolated from peptide mass matching in the program was $43.7 \%$ (Table I). 
Table I. The upregulated proteins identified in ICC.

\begin{tabular}{|c|c|c|c|c|c|c|}
\hline $\begin{array}{l}\text { SSP } \\
\text { no. }\end{array}$ & Accession no. & Protein name & $\begin{array}{c}\mathrm{MW} \\
(\mathrm{kDa}) / \mathrm{pI}\end{array}$ & $\begin{array}{c}\text { Matched } \\
\text { peptides }(\%)\end{array}$ & $\begin{array}{c}\text { Sequence } \\
\text { coverage }(\%)\end{array}$ & P-value \\
\hline 0013 & P60660 & Myosin light polypeptide 6 & $16.9 / 4.6$ & 26 & 30.5 & 0.0126 \\
\hline 0111 & P28065 & Proteasome subunit $\beta$ type- 9 precursor & $23.3 / 4.9$ & 40 & 23.7 & 0.0190 \\
\hline 0301 & P07951 & Tropomyosin $\beta$ chain & $32.9 / 4.7$ & 65 & 35.9 & 0.0031 \\
\hline 0302 & Q9BSJ2 & Proliferating cell nuclear antigen & $28.8 / 4.6$ & 44 & 31.0 & 0.0059 \\
\hline 0305 & P09493 & Tropomyosin $\alpha-1$ chain & $32.7 / 4.7$ & 33 & 21.1 & 0.0027 \\
\hline 0306 & P09493 & Tropomyosin $\alpha-1$ chain & $32.7 / 4.7$ & 56 & 25.0 & 0.0191 \\
\hline 0312 & P61978 & Heterogeneous nuclear ribonucleoprotein $\mathrm{K}$ & $50.9 / 5.4$ & 33 & 18.1 & 0.0063 \\
\hline 0603 & P49585 & Choline-phosphate cytidylyltransferase A & $41.7 / 6.8$ & 28 & 13.4 & 0.0092 \\
\hline 0606 & Q12765 & Secernin-1 & $46.4 / 4.7$ & 22 & 13.0 & 0.0073 \\
\hline 1006 & gil37014297 & Immunoglobulin $\mathrm{E}$ heavy chain variable region & $14.6 / 4.86$ & 8 & 17.0 & $6.2 \times 10^{-5}$ \\
\hline 1008 & Q15814 & Tubulin-specific chaperone $\mathrm{C}$ & $39.2 / 5.6$ & 33 & 13.9 & 0.0092 \\
\hline 1018 & CPLX4_Human & Complexin-4 & $18.4 / 4.5$ & 8 & 17.0 & 0.0336 \\
\hline 1101 & $\mathrm{P} 04632$ & Calpain small subunit 1 & $28.3 / 5.0$ & 46 & 29.5 & 0.0093 \\
\hline 1105 & P52565 & Rho GDP-dissociation inhibitor 1 & $23.2 / 5.0$ & 22 & 21.1 & 0.0114 \\
\hline 1108 & P63104 & $14-3-3$ protein zeta/ $\delta$ & $27.7 / 4.7$ & 47 & 48.6 & 0.0492 \\
\hline 1210 & Q99426 & Tubulin folding cofactor B & $27.3 / 5.1$ & 25 & 23.0 & 0.0036 \\
\hline 1211 & O00299 & Chloride intracellular channel protein 1 & $26.9 / 5.1$ & 35 & 23.7 & 0.0008 \\
\hline 1214 & gil119627265 & hCG1643319 & $28.1 / 5.6$ & 14 & 18.0 & 0.0354 \\
\hline 1301 & P35237 & Serpin B6, Placental thrombin inhibitor & $42.6 / 5.2$ & 45 & 30.1 & 0.0202 \\
\hline 1415 & Q14320 & Protein FAM50A & $40.2 / 6.4$ & 30 & 13.3 & 0.0108 \\
\hline 1421 & P60709 & Actin, cytoplasmic 1 & $41.7 / 5.3$ & 30 & 23.2 & 0.0243 \\
\hline 1514 & P50452 & Serpin B8 & $42.8 / 5.4$ & 29 & 15.0 & 0.0414 \\
\hline 1607 & P01009 & $\alpha-1$-antitrypsin precursor & $46.7 / 5.4$ & 38 & 24.2 & 0.0227 \\
\hline 2005 & O75368 & $\begin{array}{l}\text { SH3 domain-binding glutamic } \\
\text { acid-rich-like protein }\end{array}$ & $12.8 / 5.2$ & 27 & 28.9 & 0.0015 \\
\hline 2010 & Q8WU39 & Proapoptotic caspase adapter protein & $20.7 / 5.4$ & 37 & 34.9 & 0.0002 \\
\hline 2208 & P19623 & Spermidine synthase & $33.8 / 5.3$ & 23 & 16.2 & 0.0459 \\
\hline 2302 & Q04323 & SAPK substrate protein 1 & $33.3 / 5.2$ & 33 & 21.5 & 0.0068 \\
\hline 2305 & O76003 & Glutaredoxin-3 & $37.4 / 5.3$ & 31 & 23.9 & 0.0153 \\
\hline 3001 & Q14019 & Coactosin-like protein & $15.9 / 5.5$ & 53 & 50.7 & 0.0004 \\
\hline 3113 & Q9BY32 & Inosine triphosphate pyrophosphatase & $21.4 / 5.5$ & 36 & 29.9 & 0.0013 \\
\hline 3301 & P60709 & Actin, cytoplasmic 1 & $41.7 / 5.3$ & 43 & 22.7 & 0.0033 \\
\hline 3303 & P60709 & Actin, cytoplasmic 1 & $41.7 / 5.3$ & 35 & 17.1 & 0.0129 \\
\hline 3704 & P10809 & Hsp60 & $61.1 / 5.7$ & 52 & 21.3 & 0.0133 \\
\hline 4008 & P26447 & Metastasin & $11.7 / 5.9$ & 33 & 36.6 & 0.0036 \\
\hline 4408 & P36952 & Maspin & $42.1 / 5.7$ & 46 & 24.8 & 0.0115 \\
\hline 4607 & P48637 & Glutathione synthetase & $52.4 / 5.7$ & 47 & 16.9 & 0.0008 \\
\hline 4703 & Q99829 & Copine-1 (Copine I) & $59.1 / 5.5$ & 26 & 5.8 & 0.0063 \\
\hline 4826 & Q02156 & nPKC-epsilon & $83.7 / 6.7$ & 31 & 10.9 & 0.0173 \\
\hline 5008 & P31949 & Calgizzarin & $11.7 / 6.6$ & 41 & 49.5 & 0.0004 \\
\hline 5104 & P09211 & Glutathione S-transferase P & $23.4 / 5.4$ & 30 & 40.5 & 0.0188 \\
\hline 5405 & P36952 & Serpin B5 precursor & $42.1 / 5.7$ & 50 & 54.7 & 0.0187 \\
\hline 5411 & Q03154 & Aminoacylase-1 & $45.9 / 5.8$ & 50 & 37.3 & 0.0031 \\
\hline 5414 & $\mathrm{P} 40121$ & Macrophage-capping protein & $38.5 / 5.9$ & 53 & 29.6 & 0.0171 \\
\hline 5502 & P35998 & $26 \mathrm{~S}$ protease regulatory subunit 7 & $48.6 / 5.7$ & 30 & 18.7 & 0.0122 \\
\hline 5615 & Q96KP4 & Cytosolic non-specific dipeptidase & $52.9 / 5.7$ & 46 & 17.7 & 0.0389 \\
\hline 5802 & P06396 & Gelsolin precursor & $85.7 / 5.9$ & 54 & 19.8 & 0.0010 \\
\hline 6001 & P80511 & Calgranulin-C & $10.6 / 5.8$ & 25 & 45.7 & 0.0373 \\
\hline 6010 & Q01469 & Fatty acid-binding protein 5 & $15.2 / 6.6$ & 31 & 43.7 & 0.0125 \\
\hline 6112 & Q9ULZ3 & Target of methylation induced silencing 1 & $21.6 / 6.0$ & 36 & 19.5 & 0.0081 \\
\hline 6602 & Q8N1M1 & Bestrophin-3 & $76.1 / 6.1$ & 26 & 6.0 & 0.0015 \\
\hline
\end{tabular}


Table II. The downregulated proteins identified in ICC.

\begin{tabular}{|c|c|c|c|c|c|c|}
\hline SSP no. & Accession no. & Protein name & $\begin{array}{c}\mathrm{MW} \\
(\mathrm{kDa}) / \mathrm{pI}\end{array}$ & $\begin{array}{c}\text { Matched } \\
\text { peptides }(\%)\end{array}$ & $\begin{array}{c}\text { Sequence } \\
\text { coverage }(\%)\end{array}$ & P-value \\
\hline 1104 & P21964 & Catechol O-methyltransferase & $30.0 / 5.3$ & 38 & 32.8 & 0.0128 \\
\hline 2308 & Q15417 & Calponin-3 & $36.4 / 5.7$ & 26 & 17.9 & 0.0031 \\
\hline 2702 & Q9BQE3 & Tubulin $\alpha-1 C$ chain & $49.9 / 5.0$ & 40 & 39.2 & 0.0061 \\
\hline 2720 & P08670 & Vimentin & $53.7 / 5.1$ & 23 & 12.2 & 0.0185 \\
\hline 3215 & Q9HC38 & Glyoxalase domain-containing protein 4 & $34.8 / 5.4$ & 29 & 18.2 & 0.0126 \\
\hline 4011 & Q12988 & Heat shock protein $\beta-3$ & $17.0 / 5.7$ & 33 & 18.0 & 0.0001 \\
\hline 4013 & Q99584 & Protein S100-A13 & $11.5 / 5.9$ & 28 & 39.8 & 0.0198 \\
\hline 4017 & Q9BV57 & $\begin{array}{l}\text { 1,2-dihydroxy-3-keto-5-methylthiopentene } \\
\text { dioxygenase }\end{array}$ & $21.5 / 5.4$ & 35 & 40.2 & 0.0008 \\
\hline 4121 & P07203 & Glutathione peroxidase 1 & $21.9 / 6.1$ & 25 & 23.9 & 0.0155 \\
\hline 4317 & P47755 & F-actin-capping protein subunit $\alpha-2$ & $32.9 / 5.6$ & 35 & 33.2 & 0.0388 \\
\hline 4507 & Q9Y2T3 & Guanine deaminase & $51.0 / 5.4$ & 52 & 33.7 & 0.0406 \\
\hline 4708 & P48643 & TCP-1-epsilon & $59.7 / 5.5$ & 50 & 29.9 & 0.0023 \\
\hline 5107 & P62993 & Growth factor receptor-bound protein 2 & $25.2 / 5.9$ & 40 & 32.7 & 0.0133 \\
\hline 5219 & P50053 & Ketohexokinase & $32.7 / 5.6$ & 25 & 20.1 & 0.0331 \\
\hline 5610 & P37837 & Transaldolase & $37.5 / 6.4$ & 46 & 23.7 & 0.0022 \\
\hline 6411 & P30740 & Leukocyte elastase inhibitor (LEI) & $42.7 / 5.9$ & 55 & 32.7 & 0.0091 \\
\hline 8015 & P68871 & Hemoglobin subunit $\beta$ & $16.0 / 6.7$ & 27 & 46.9 & 0.0189 \\
\hline
\end{tabular}

A

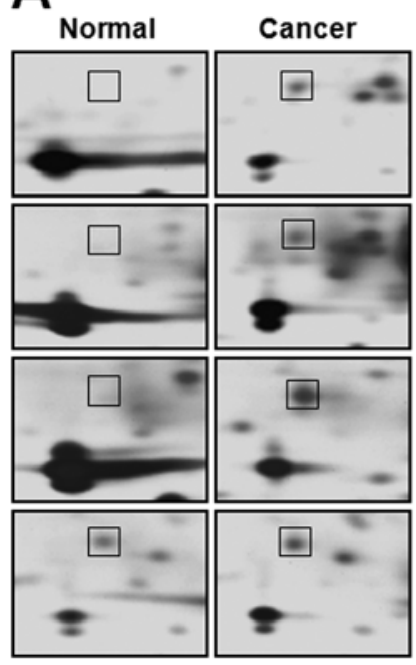

B
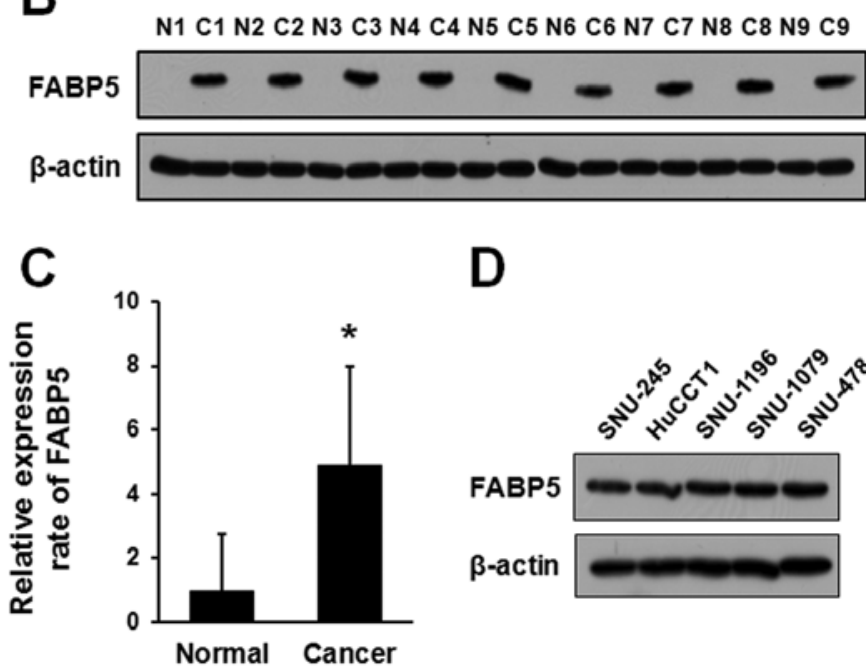

D

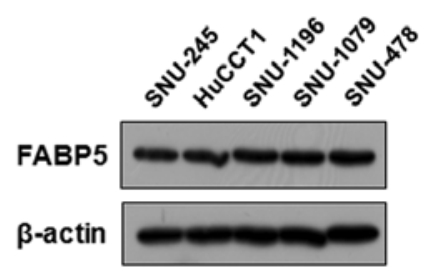

Figure 1. The expression of FABP5 protein in cholangiocarcinoma tissues and cell lines. (A) A representative result of 2-DE proteomic analysis for FABP5 expression in ICC. FABP5 expression is upregulated in all ICC tissues (marked with box) compared to normal bile duct tissues. Nine representative cases (B) and summary (C) of FABP5 expression in primary ICC (C) and paired normal bile duct tissues (N) examined by western blot analysis. The protein expression levels of FABP5 were normalized to $\beta$-actin levels. "Indicates a significant $(\mathrm{P}<0.001)$ increase as compared to normal bile duct tissues. (D) Western blot anlaysis of FABP5 expression in cholangiocarcinoma cell lines. $\beta$-actin was used as an internal control. The FABP5 was ubiquitously expressed in all cholangiocarcinoma cell lines examined.

Expression levels of FABP5 were also examined by western blot analysis in paired ICC and normal bile duct tissues obtained from 16 patients. Nine representative samples of western blotting for FABP5 expression are shown in Fig. 1B. Western blot analysis of FABP5 expression in the same sample as those used for 2-DE confirmed that FABP5 was highly expressed in ICC samples, while the normal bile duct from the same patients showed undetectable FABP5 levels. As shown in Fig. 1C, the upregulation ratio of FABP5 in ICC to normal bile duct tissues was about 5 -fold. We next compared expression of FABP5 in cholangiocarcinoma cell lines (Fig. 1D). Western blot analysis revealed that all five cholangiocarcinoma cell lines highly expressed FABP5. 

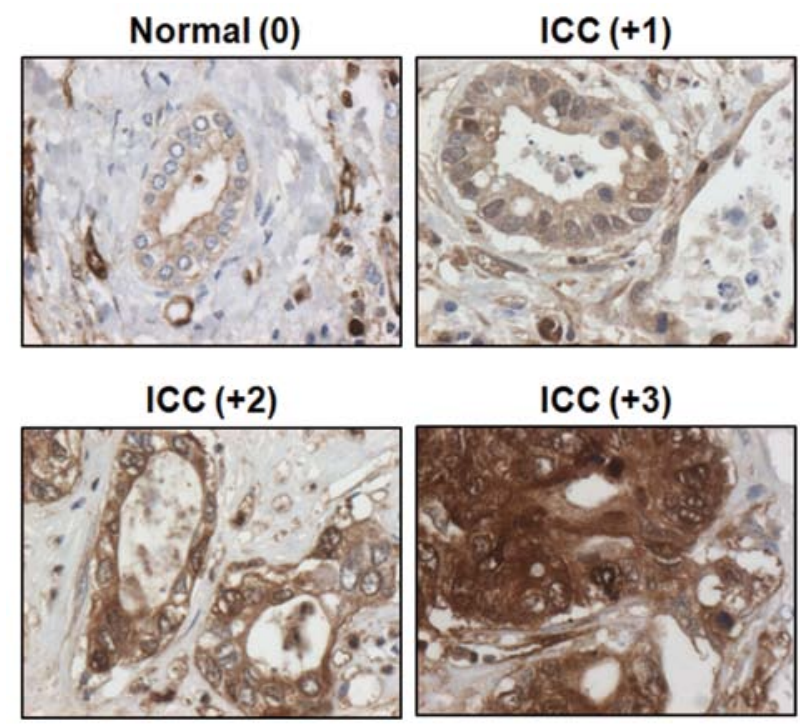

Figure 2. Immunohistochemistry of FABP5 protein in section from the experiments with samples from 16 ICC patients. Immunohistochemical staining was interpretated and categorized by an arbitrary semi-quantitative scale as 0 (negative staining), $+1(0-20 \%$ positive), $+2(20-40 \%$ positive), and +3 ( $>40 \%$ positive). Original magnification, $\mathrm{x} 200$.

Table III. Correlation between FABP5 expression and clinicopathological characteristics.

\begin{tabular}{|c|c|c|c|}
\hline \multirow[b]{2}{*}{$\begin{array}{l}\text { Pathological } \\
\text { variables }\end{array}$} & \multicolumn{3}{|c|}{ Level of expression FABP5 } \\
\hline & $\begin{array}{c}\text { Weak }^{\mathrm{a}} \\
(\mathrm{n}=18)(\%)\end{array}$ & $\begin{array}{c}\text { Strong }^{\mathrm{b}} \\
(\mathrm{n}=25)(\%)\end{array}$ & P-value \\
\hline \multicolumn{4}{|l|}{ Size (cm) } \\
\hline$<5$ & $12(57.1)$ & $9(42.9)$ & 0.047 \\
\hline$>5$ & $6(27.3)$ & $16(72.7)$ & \\
\hline \multicolumn{4}{|l|}{ LN metastasis } \\
\hline Negative & $18(51.4)$ & $17(48.6)$ & 0.013 \\
\hline Positive & $0(0)$ & $8(100)$ & \\
\hline \multicolumn{4}{|l|}{ Angioinvasion } \\
\hline Negative & $18(48.6)$ & $19(51.4)$ & 0.032 \\
\hline Positive & $0(0)$ & $6(100)$ & \\
\hline \multicolumn{4}{|l|}{ Perineural invasion } \\
\hline Negative & $16(45.7)$ & $19(54.3)$ & 0.434 \\
\hline Positive & $2(25.0)$ & $6(75.0)$ & \\
\hline \multicolumn{4}{|l|}{ Multifocality } \\
\hline Single & $16(45.7)$ & $19(54.3)$ & 0.434 \\
\hline Multiple & $2(25.0)$ & $6(75.0)$ & \\
\hline \multicolumn{4}{|l|}{ Differentiation } \\
\hline Well to moderate & $17(50.0)$ & $17(50.0)$ & 0.339 \\
\hline Poor & $1(11.1)$ & $8(88.9)$ & \\
\hline \multicolumn{4}{|l|}{ Stage } \\
\hline I & $15(62.5)$ & $9(37.5)$ & 0.007 \\
\hline II & $2(22.2)$ & $7(77.8)$ & \\
\hline III and IV & $1(10.0)$ & $9(90.0)$ & \\
\hline
\end{tabular}

Immunointensity was scored on an arbitrary scale of 0 , negative; +1 , $0-20 \%$ positive; $+2,20-40 \%$ positive; and $+3,>40 \%$ positive intense.

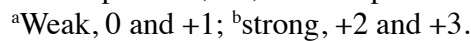

FABP5 was primarily observed in the cytoplasm of epithelial cells in both cancerous and non-cancerous tissues (Fig. 2). Immunohistochemical staining was interpretated and categorized by an arbitrary semi-quantitative scale as 0 (negative staining), +1 ( $0 \sim 20 \%$ positive), +2 (20 40\% positive), and +3 $(>40 \%$ positive) by pathologists. All normal bile ducts stained weakly for FABP5 $(0$ or +1$)$, while the strong staining intensity was verified in ICC $(+1$ to +3$)$.

Correlation between FABP5 expression and clinicopathological variables. In order to investigate the clinical significance of FABP5 expression, we performed immunohistochemical analysis on tissue sections from a larger population of ICC patients. A total of 43 patients with MF type ICC who underwent several types of major hepatectomy and lymph node dissection, either alone or in conjunction with extrahepatic bile duct resection were enrolled in this study. There were 33 men and 10 women with a mean age of 63.21 years (range, 47-80 years). If the tumor seemed to invade adjacent organs grossly in the operative field, combined resection was performed to achieve negative resection margins. Clinical data and outcome of the patients were collected from medical records retrospectively. The results of the study revealed weak FABP5 staining $(0$ or +1$)$ in 18 of the 43 cases, which were classified as the weak positive group. The remaining 25 cases exhibited strong FABP5 staining and were classified as the strong positive group $(+2$ or +3$)$. The expression levels of FABP5 were compared with the clinical and pathological characteristics of each case of MF type ICC, including size, differentiation, lymph node metastasis, vascular invasion, perineural invasion, multiplicity and stage (Table III). All eight patients with lymph node metastasis showed strong staining intensity against FABP5. Univariate analysis revealed that tumor size $(\mathrm{P}=0.047)$, lymph node metastasis $(\mathrm{P}=0.013)$, angio-invasion $(\mathrm{P}=0.032)$, and staging $(\mathrm{P}=0.007)$ significantly correlated with expression levels of FABP5. 

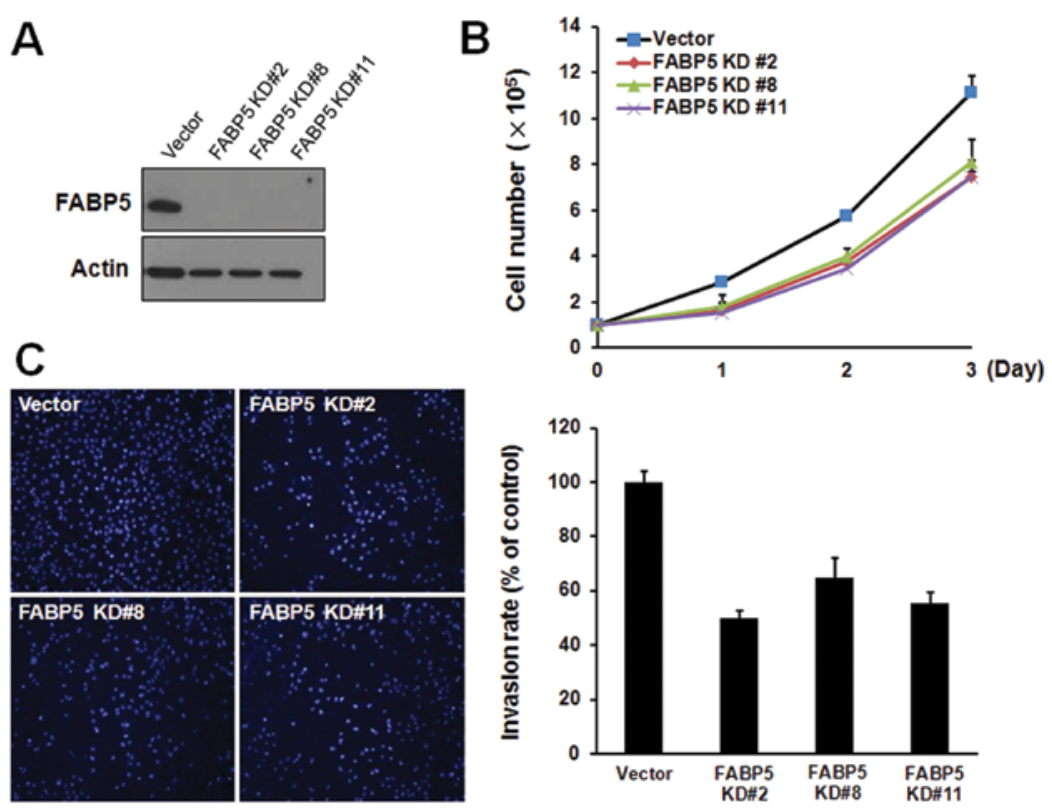

Figure 3. The effect of FABP5 knockdown on cholangiocarcinoma cell proliferation and invasion. (A) Western blot analysis of FABP5 in cell clones silenced using FABP5-specific shRNA. (B) The cell proliferation rate was determined by cell count using trypan blue exclusion assay. The growth curve revealed that downregulation of FABP5 reduced the proliferation of HuCCT1 cells. (C) Matrigel invasion assay of HuCCT1 cell clones stably transfected with FABP5specific shRNA or empty vector control. A total of $1 \times 10^{5}$ cells were plated on the upper chamber of transwell filters ( $8 \mu \mathrm{m}$ pore) occluded by a thin layer of Matrigel basement membrane matrix. After $24 \mathrm{~h}$, the invasive cells that were able to invade into the lower surface of the filter were fixed, stained with DAPI and counted under the fluorescent microscope. The graph contains data from three independent experiments (right panel).

A

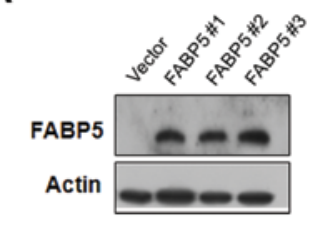

C

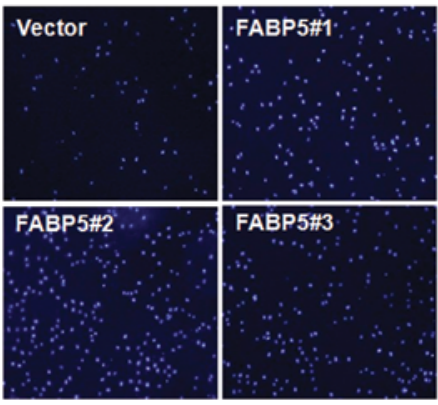

\section{B}
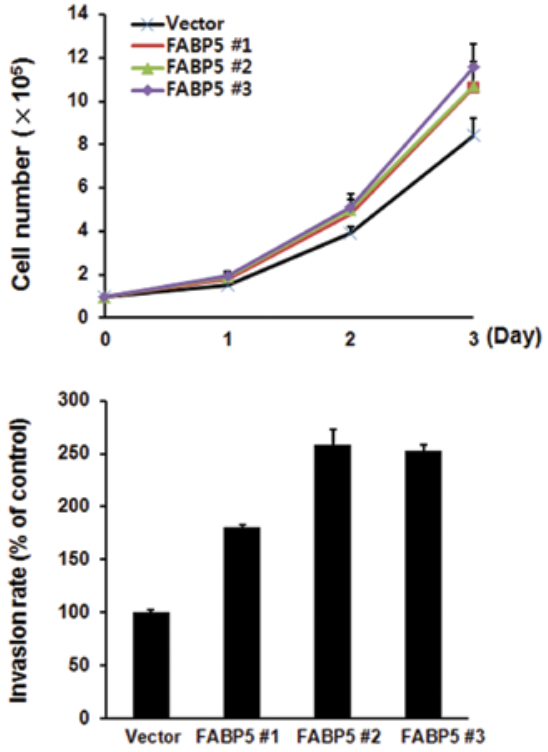

Figure 4. Enhanced cell proliferation and invasion of hepatoma cell line Hep3B stably transfected with the FABP5 cDNA. (A) Overexpression of the FABP5 protein in Hep3B cells stably transfected with pcDNA3.1/FABP5 measured by western blot analysis. (B) Cell proliferation assay by cell counting. Cell proliferation statistically significantly increased in Hep3B cell clones by stable transfection with a plasmid encoding the FABP5 protein. (C) Invasion assay was performed as described in Fig. 3C. FABP5 overexpression significantly enhanced Hep3B cell invasion. The graph contains data from three independent experiments (right panel).

Effect of FABP5 on the proliferation and invasion of ICC cells. Suppression of FABP5 expression in oral squamous cell carcinoma has been reported to inhibit proliferation and invasion (19). Therefore, we first investigated whether FABP5 was critical for the proliferation of cholangiocarcinoma cells. We used a short hairpin RNA (shRNA) to silence the expression of FABP5. HuCCT1 cells were transfected with control shRNA or FABP5 specific shRNA plasmid. After puromycin $(2 \mu \mathrm{g} / \mathrm{ml})$ selection, western blot analysis confirmed that FABP5-shRNA clones (named FABP5-KD \#2, FABP5-KD \#8, FABP5-KD \#11) showed an almost complete silence of FABP5 expression compared to control shRNA clones (Fig. 3A). Depletion of FABP5 expression significantly $(\mathrm{P}<0.01)$ inhibited the cell proliferation rate of HuCCT1 cells without significant increase 
of dead cells (Fig. 3B). To examine the effects of FABP5 depletion on tumor cell invasion in FABP5-depleting HuCCT1 clones, we then performed in vitro invasion assay. FABP5 depletion caused a significant reduction in the invasiveness of FABP5-depleted HuCCT1 cells (Fig. 3C).

To confirm the enhancing effects of FABP5 on cell proliferation and invasion, we also examined the effects of the FABP5 overexpression on the FABP5-negative hepatoma cell line Hep3B by stable transfection with a plasmid encoding the FABP5 protein. After G418 $(2 \mathrm{mg} / \mathrm{ml})$ selection, the expression of FABP5 in selected clones (named FABP5 \#1, FABP5 \#2, FABP5 \#3) was determined by western blotting (Fig. 4A). Cell proliferation rate, counted by trypan blue assay (Fig. 4B) and Matrigel invasion assays (Fig. 4C) of FABP5 overexpressing cell clones were significantly increased compared to the control vector expressing clones. Taking these results together, the expression of FABP5 seems to be involved in the increased cell proliferation and invasion of ICC cells.

\section{Discussion}

Carcinogenesis is a multistep process involving cumulative genetic and epigenetic alterations such as the activation of oncogenes or the inactivation of tumor suppressor genes (1). Recent extensive molecular studies of cholangiocarcinoma demonstrated that numerous molecular modifications, including dysregulation of cell growth and survival pathways, aberrant gene expression, invasion and metastasis, and tumor microenvironment play important roles in multistep cholangiocarcinogenesis (20). ICC is a good model for the study of multistep carcinogenesis because of the progress from hyperplasia to dysplasia, and finally to adenocarcinoma (21).

To gain a comprehensive understanding of cellular function, the logical method of analysis is proteomics, in which the global protein expression patterns in a cell, tissue, or organism can be analyzed. In general, proteomics deal with the largescale determination of gene and cell function directly at the protein level. Many proteomic studies investigating HCC have been done already, but only a few studies using ICC tissues or cell lines have been published $(22,23)$. In this study, we obtained the protein profiles of the normal bile duct and ICC tissues. By comparing these profiles, we obtained 67 proteins that showed differential expressions (more than a 3 -fold increased or decreased, $\mathrm{P}<0.05$ ) in the ICC tissues (Tables I and II). Fifty proteins, including FABP5, proapoptotic caspase adapter protein (PACAP), metastasin, protein kinase $\mathrm{C}$ epsilon $(\mathrm{PKC} \varepsilon)$, calgizzarin, target of methylation-induced silencing 1 (TMS1), calgranulin $C$ and maspin, were upregulated in the ICC tissues, while 17 proteins, including heat shock protein $\beta-3$ (HspB3), glyoxalase domain-containing protein 4 (GLOD4), glutathione peroxidase $1, \mathrm{~T}$-complex protein 1 subunit epsilon (TCP-1ع), ketohexokinase and transaldolase, were downregulated. Among the set of differentially expressed proteins, we identified several proteins previously described as proteins that are involved in ICC progression or differentially expressed by ICC. Three proteins, FABP5, TMS1 and ketohexokinase in ICC were newly identified in this study. Subsequently, we focused on FABP5, which have previously been reported as upregulated protein in other cancers. FABP5 was barely detectable in normal bile duct tissues. However, the expression was increased in ICC when the rate of increase in ICC was more evident in western blotting (Fig. 1). Furthermore, our results were validated by immunohistochemical staining of 43 tumor sections. These results showed that the expression of FABP5 was suitably visible in the inflammatory bile duct, and was greatly increased in many ICC tissues (Fig. 2).

Comparative analysis of the clinicopathological characteristics of carcinomas with weak FABP5 staining $(0$ or +1$)$ and those with strong FABP5 staining $(2+$ or +3$)$ indicated that tumors with strong FABP5 expression were significantly associated with tumor size $(\mathrm{P}=0.047)$, lymph node metastasis $(\mathrm{P}=0.013)$, angioinvasion $(\mathrm{P}=0.032)$ and staging $(\mathrm{P}=0.007)$ (Table 3). Lymph node metastasis is a negative prognostic factor in patients with ICC (3). Analysis of prognostic factors after surgical resection demonstrated that mixed type of mass-forming (MF) and periductal-infiltrating (PI) ICC, lymph node metastasis, and vascular invasion were important predictive factors related to poor survival (3). Another study revealed that lymph node metastasis was closely associated with negative prognostic factors including MF or PI type, poorly or undifferentiated tumors, vascular invasion, and perineural invasion (4). In the current study, all of the 43 enrolled patients had MF type ICC and underwent standard lymph node dissection, and lymph node metastasis was found in eight cases (18.6\%). Cancerous tissues from all patients with lymph node metastasis exhibited strong staining for FABP5. Our results demonstrated that increased expression of FABP5 is significantly correlated with known factors of poor prognosis and poor outcome.

FABPs are 14-to-15 $\mathrm{kDa}$ proteins of 126-134 amino acids in length, and are designated according to the tissue from which they were first isolated or identified, such as liver FABP (L-FABP), heart FABP (H-FABP), adipose FABP (A-FABP) and epidermal FABP (E-FABP or FABP5). Among them, E-FABP, also known as psoriasis-associated (PA)-FABP, keratinocyte FABP, was originally isolated from psoriatic skin samples (8). It is a small (15.2 $\mathrm{kDa}$ ) cytoplasmic protein and has binding activity typical of the FABP family of proteins in that it has a high affinity for long-chain fatty acids. Several recent studies have implicated FABP5 in tumorigenesis. Adamson et al demonstrated that FABP5 was increased in prostatic carcinoma cells, and that suppression of FABP5 expression inhibited the expression of vascular endothelial growth factor (VEGF) (12). FABP5 contributes to metastasis by upregulating the expression of the VEGF gene, which is one of the most potent stimulators of angiogenesis (24). In addition to prostatic carcinoma, a recent study reported that FABP5 may also play a role in the malignant progression of pancreatic carcinoma, and that overexpression of FABP5 in chemo-resistant pancreatic cancer cell lines enhances intracellular compartmentation or removal of cytotoxic drugs (10). Another proteomic study using human HCC cell lines revealed increased expression of FABP5 in HCC tissues compared with normal hepatocytes (25). A more recent study reported that suppression of FABP5 expression in oral squamous cell carcinoma inhibited cell proliferation and invasion (19). To elucidate the biological significance of elevated levels of FABP5, studies utilizing siRNA-mediated silencing of FABP5 were performed. We showed that FABP5 is highly expressed in ICC cells and 
is involved in the enhanced cell proliferation and invasion through experiments that used both FABP5 downregulation and upregulation. The shRNA-mediated silencing of FABP5 in HuCCT1 cells significantly inhibited cell proliferation and invasion (Fig. 3). On the contrary, Hep3B cells stably expressing FABP5 showed increased invasion and proliferation abilities of cancer cell (Fig. 4). Although the precise role of FABP5 in carcinogenesis is not clear, it is likely to be involved in the binding and transport of intracellular fatty acids, some of which may be signaling molecules involved in carcinogenesis (26). Intracellular fatty acids (FAs) are bound by FABPs, which are important carriers of the intracellular FAs. Elevated expression of FABPs may result in the increased mobilization of FAs, and thus enhance FA signaling activity.

FAs, especially polyunsaturated FAs (PUFAs), such as arachidonic acid (AA) and linoleic acid, can act as signaling molecules recognized by the nuclear peroxisome proliferator-activated receptor (PPAR) (27). PPAR family members are nuclear receptors known to regulate the transcription of many genes involved in lipid metabolism (28). Of the three PPAR isotypes (PPAR $\alpha$, PPAR $\beta / \delta$ and PPAR $\gamma$ ), PPAR $\beta / \delta$ is known to be a downstream gene of $\mathrm{Wnt} / \beta$-catenin signaling pathway and it has been shown to promote human cholangiocarcioma cell growth (29). It was demonstrated that the positive feedback loop between PPAR $\beta / \delta$ and prostaglandin E2 (PGE2) played an important role in cholangiocarcinoma cell growth in human cholangiocarcinoma cell lines. Activation of PPAR $\beta / \delta$ has also been shown to increase the expression of cyclooxygenase-2 (COX-2) and the production of COX-2-derived PGE2, resulting in subsequent activation of PPAR $\beta / \delta$ through $c P L A 2$ a phosphorylation-induced AA release $(30,31)$. In turn, cPLA2a-derived AA activates PPAR $\beta / \delta$ in the nucleus. This positive feedback loop is likely important for increased E-FABP expression in cholangiocarcinoma.

In conclusion, the current study showed that the expression of FABP5 was significantly increased in ICC with lymph node metastasis, vascular invasion, and large tumor size and it can regulate proliferation and invasion in cholangiocarcinoma cells in vitro. This finding suggests a potential role of FABP5 in tumor progression. We propose that FABP5 may serve as a prognostic biomarker and potential therapeutic target for ICC.

\section{Acknowledgements}

This study was supported by a grant from the National R\&D Program for Cancer Control, Ministry for Health, Welfare and Family Affairs, Republic of Korea (0820050) and a clinical research grant from the Gyeongsang National University Hospital (2007 and GNUHCRF 2010-001).

\section{References}

1. Blechacz B and Gores GJ: Cholangiocarcinoma: advances in pathogenesis, diagnosis and treatment. Hepatology 48: 308-321, 2008.

2. Okabayashi T, Yamamoto J, Kosuge T, Shimada K, Yamasaki S, Takayama T and Makuuchi M: A new staging system for massforming intrahepatic cholangiocarcinoma. Cancer 92: 2374-2383, 2001.
3. Guglielmi A, Ruzzenente A, Campagnaro T, Pachera S Valdegamberi A, Nicoli P, Cappellani A, Malfermoni G and Iacono C: Intrahepatic cholangiocarcinoma: prognostic factors after surgical resection. World J Surg 33: 1247-1254, 2009.

4. Choi SB, Kim KS, Choi JY, Park SW, Choi JS, Lee WJ and Chung JB: The prognosis and survival outcome of intrahepatic cholangiocarcinoma following surgical resection: association of lymph node metastasis and lymph node dissection with survival. Ann Surg Oncol 16: 3048-3056, 2009.

5. Zimmerman AW and Veerkamp JH: New insights into the structure and function of fatty acid-binding proteins. Cell Mol Life Sci 59: 1096-1116, 2002

6. Coe NR and Bernlohr DA: Physiological properties and functions of intracellular fatty acid-binding proteins. Biochim Biophys Acta 1391: 287-306, 1998.

7. Glatz JF and Storch J: Unravelling the significance of cellular fatty acid-binding proteins. Curr Opin Lipidol 12: 267-274, 2001.

8. Madsen P, Rasmussen HH, Leffers H, Honoré B and Celis JE: Molecular cloning and expression of a novel keratinocyte protein (psoriasis-associated fatty acid-binding protein [PA-FABP]) that is highly up-regulated in psoriatic skin and that shares similarity to fatty acid-binding proteins. J Invest Dermatol 99: 299-305, 1992.

9. Haunerland NH and Spener F: Fatty acid-binding proteins insights from genetic manipulations. Prog Lipid Res 43: 328-349, 2004.

10. Sinha P, Hütter G, Köttgen E, Dietel M, Schadendorf D and Lage H: Increased expression of epidermal fatty acid binding protein, cofilin and 14-3-3-sigma (stratifin) detected by twodimensional gel electrophoresis, mass spectrometry and microsequencing of drug-resistant human adenocarcinoma of the pancreas. Electrophoresis 20: 2952-2960, 1999.

11. Ostergaard M, Rasmussen $\mathrm{HH}$, Nielsen HV, Vorum $\mathrm{H}$, Orntoft TF, Wolf $\mathrm{H}$ and Celis JE: Proteome profiling of bladder squamous cell carcinomas: identification of markers that define their degree of differentiation. Cancer Res 57: 4111-4117, 1997

12. Adamson J, Morgan EA, Beesley C, Mei Y, Foster CS, Fujii H, Rudland PS, Smith PH and Ke Y: High-level expression of cutaneous fatty acid-binding protein in prostatic carcinomas and its effect on tumorigenicity. Oncogene 22: 2739-2749, 2003.

13. Xu HE, Lambert MH and Montana VG: Molecular recognition of fatty acids by peroxisome proliferator-activated receptors. Mol Cell 3: 397-403, 1999.

14. Morgan E, Kannan-Thulasiraman P and Noy N: Involvement of fatty acid binding protein 5 and PPAR $\beta / \delta$ in prostate cancer cell growth. PPAR Res 2010: 234629, 2010.

15. Jung EJ, Moon HG and Cho BI: Galectin-1 expression in cancer-associated stromal cells correlates tumor invasiveness and tumor progression in breast cancer. Int J Cancer 120: 2331-2338, 2007

16. Landry F, Lombardo CR and Smith JW: A method for application of samples to matrix-assisted laser desorption ionization time-offlight targets that enhances peptide detection. Anal Biochem 279: 1-8, 2000 .

17. Yates JR: Database searching using mass spectrometry data. Electrophoresis 19: 893-900, 1998.

18. Hsu SM, Raine L and Fanger H: Use of avidin-biotin-peroxidase complex $(\mathrm{ABC})$ in immunoperoxidase techniques: a comparison between $\mathrm{ABC}$ and unlabeled antibody (PAP) procedures. J Histochem Cytochem 29: 577-580, 1981.

19. Fang LY, Wong TY, Chiang WF and Chen YL: Fatty-acidbinding protein 5 promotes cell proliferation and invasion in oral squamous cell carcinoma. J Oral Pathol Med 39: 342-348, 2010.

20. Sirica AE: Cholangiocarcinoma: molecular targeting strategies for chemoprevention and therapy. Hepatology 41: 5-15, 2005.

21. Shimonishi T, Sasaki M and Nakanuma Y: Precancerous lesions of intrahepatic cholangiocarcinoma. J Hepatobiliary Pancreat Surg 7: 542-550, 2000.

22. Kawase H, Fujii K, Miyamoto M, Kubota KC, Hirano S, Kondo S and Inagaki F: Differential LC-MS-based proteomics of surgical human cholangiocarcinoma tissues. J Proteome Res 8: 4092-4103, 2009.

23. Srisomsap C, Sawangareetrakul P, Subhasitanont $P$, Panichakul T, Keeratichamroen S, Lirdprapamongkol K, Chokchaichamnankit D, Sirisinha S and Svasti J: Proteomic analysis of cholangiocarcinoma cell line. Proteomics 4: 1135-1144, 2004. 
24. Jing C, Beesley C, Foster CS, Chen H, Rudland PS, West DC, Fujii H, Smith PH and Ke Y: Human cutaneous fatty acid-binding protein induces metastasis by up-regulating the expression of vascular endothelial growth factor gene in rat Rama 37 model cells. Cancer Res 61: 4357-4364, 2001.

25. Fujii K, Kondo T, Yokoo H, Yamada T, Iwatsuki $\mathrm{K}$ and Hirohashi S: Proteomic study of human hepatocellular carcinoma using two-dimensional difference gel electrophoresis with saturation cysteine dye. Proteomics 5: 1411-1422, 2005.

26. Glatz JFC, Schaap FG, Binas B, Bonen A, van der Vusse GJ and Luiken J: Cytoplasmic fatty acid-binding protein facilitates fatty acid utilization by skeletal muscle. Acta Physiol Scand 178 367-371, 2003.

27. Schroeder F, Petrescu AD, Huang H, Atshaves BP, McIntosh AL, Martin GG, Hostetler HA, Vespa A, Landrock D and Landrock KK: Role of fatty acid binding proteins and long chain fatty acids in modulating nuclear receptors and gene transcription. Lipids 43: 1-17, 2008.
28. Desvergne B and Wahli W: Peroxisome proliferator-activated receptors: nuclear control of metabolism. Endocr Rev 20: 649-688, 1999.

29. Lim K, Han $\mathrm{C}, \mathrm{Xu} \mathrm{L}$, Isse $\mathrm{K}$, Demetris $\mathrm{AJ}$ and $\mathrm{Wu} \mathrm{T}$ : Cyclooxygenase-2-derived prostaglandin E2 activates betacatenin in human cholangiocarcinoma cells: evidence for inhibition of these signaling pathways by omega 3 polyunsaturated fatty acids. Cancer Res 68: 553-560, 2008.

30. Wu T: Cyclooxygenase-2 and prostaglandin signaling in cholangiocarcinoma. Biochim Biophys Acta 1755: 135-150, 2005.

31. Xu L, Han C and Wu T: A novel positive feedback loop between peroxisome proliferator-activated receptor-delta and prostaglandin E2 signaling pathways for human cholangiocarcinoma cell growth. J Biol Chem 281: 33982-33996, 2006. 